\title{
PENENTUAN KEMASAN YANG REPRESENTATIF PADA KERIPIK KENTANG HOME INDUSTRI "INYAK" DENGAN METODE QUALITY FUNCTION DEPLOYMENT (QFD)
}

\author{
Deri Kurniadi \\ Sekolah Tinggi Teknologi Industri Padang \\ Email : deri.kurniadi@gmail.com
}

\begin{abstract}
Abstrak
Abstrak: Home industry "INYAK" merupakan salah satu produsen makanan ringan, yang memproduksi keripik kentang. Ibu Fitri Madonna sebagai pemilik keripik kentang "INYAK" yang berlokasi di Piai Tanah Sirah kota Padang, dalam kegiatan usahanya menghasilkan produk keripik kentang yang dikemas dalam kemasan namun kemasan yang digunakan masih terbilang sederhana yaitu menggunakan plastik bening yang biasa dipakai oleh beberapa home industri. Penjualan keripik kentang "INYAK" masih menggunakan kemasan yang sangat sederhana. Hal ini menjadi faktor penghambat pemasaran keripik kentang. Home industry "INYAK" memiliki target penjualan sebanyak $100 \mathrm{~kg} /$ minggu. Namun, data penjualan yang diperoleh dari home industry "INYAK" dalam tiga bulan terakhir yaitu sebanyak $480 \mathrm{~kg}$, sementara target penjualan yang harus dicapai sebanyak $1200 \mathrm{~kg}$ dalam tiga bulan. Oleh sebab itu perlu dilakukan penelitian terkait desain kemasan untuk membantu meningkatkan pemasaran keripik inyiak. Penelitian ini menggunakan metode Quality Function Deployment (QFD), dalam metoda ini akan dilakukan pengukuran suara konsumen terhadap kondisi kemasan keripik kentang saat ini dan pengukuran harapan serta kebutuhan konsumen terhadap kemasan keripik kentang home industry "INYAK". Hasil penelitian menunjukan rancangan kemasan keripik "INYAK" sudah representatif dimana terdapat pada kemasan memenuhi suara dan harapan konsumen diantaranya fitur pada kemasan yang lengkap berisi tentang nama usaha, komposisi produk, alamat usaha dan gambar pendukung produk serta desain yang lebih ergonomis. Dengan adanya desain kemasan yang representatif ini menunjukan penigkatan produksi keripik kentang sebanyak $150 \mathrm{~kg} /$ minggu.
\end{abstract}

Kata kunci: Kemasan, Desain, QFD

Abstract: "INYAK" home industry is one of the snack food manufacturers, which produces potato chips. Fitri Madonna as the owner of the "INYAK" potato chips' home industry located in Piai Tanah Sirah, Padang city, produces potato chips products that are packaged in fairly simple clear plastic which is commonly used by several home industries.The sale of "INYAK" potato chips still uses very simple packaging. This is an inhibiting factor in the marketing of this product. This home industry has a $100 \mathrm{~kg} /$ week sales target. However, sales data obtained in the last three months is $480 \mathrm{~kg}$, while the target is $1200 \mathrm{~kg}$ for the same period. Hence, it is necessary to conduct research related to design packaging to increase the marketing of this product.This study uses the Quality Function Deployment (QFD) method, where the consumer choice analysis will be carried out on the current condition of the potato chip packaging and the number of consumer expectations and needs for this home industry.The results showed that the packaging design for "INYAK" chips was representative where the packaging could meet the choices and expectations of consumers such as features on a complete package containing the business name, product composition, business address, and product supporting images as well as a more ergonomic design. This representative packaging design shows an increase in potato chip production by $150 \mathrm{~kg} /$ week.

Keywords: Packaging, Design, QFD 


\section{PENDAHULUAN}

Setiap perusahaan yang didirikan baik perusahaan besar maupun usaha kecil tentu mempunyai tujuan yang harus dicapai. Adapaun tujuan yang akan dicapai salah satu diantaranya adalah meningkatnya omset penjualan dan daya saing produk di pasaran. Dengan tercapainya tujuan tersebut perusahaan diharapkan dapat menghasilkan keuntungan yang optimal dalam waktu jangka panjang sehingga kelangsungan hidup perusahaan bisa dipertahankan.

Dalam situasi persaingan yang ketat, untuk meningkatkan volume penjualan dan penguasaan pasar maka semakin disadari perlunya strategi pemasaran yang tidak hanya didasarkan pada kebutuhan konsumen, tetapi juga para pesaing yang target sasaran konsumen yang sama, oleh sebab itu perusahaan perlu mengantisipasi berbagai peluang dan hambatan dalam proses pemasaran.

Dalam produksi produk makanan sangat penting diperhatikan cita rasa dan tampilan produk. Jika dilihat dari sudut pandang fungsi daya tarik, cita rasa yang tinggi tanpa memperhatikan tampilan produk maka akan kurang berhasil dalam pemasaran, begitu juga sebaliknya. Pengemasan produk dengan tampilan elegan dan unik dari produk pesaing akan memberikan nilai jual tersendiri terhadap produk yang dihasilkan.

Untuk mempertahankan kualitas produk makanan tersebut dan dengan mengembangkan produksinya di dalam persaingan yang semakin pesat maka diperlukan suatu usaha di antaranya melalui desain kemasan yang menarik. Daya tarik suatu produk itu juga tidak terlepas dari bentuk kemasannya. Oleh sebab itu kemasan seharusnya bisa mempengaruhi konsumen untuk membeli produk yang ditawarkan. Dilihat dari sisi tampilan maupun dari bentuk produk dengan warna yang sesuai sehingga produk terlihat menarik.

Kemasan merupakan suatu bidang dalam desain komunikasi visual yang memiliki tuntutan khusus karena fungsinya yang secara langsung berhadapan dengan konsumen, antara lain tuntutan teknis, komunikatif, dan kreatif serta pemasaran yang mesti diwujudkan ke dalam bahasa visual. Desain kemasan merupakan bisnis kreatif yang mengaitkan bentuk, warna, struktur, citra, material, dan elemenelemen dengan informasi produk agar produk memiliki kemasan yang informatif dan menarik saat dipasarkan. Desain kemasan juga berlaku untuk membungkus, melindungi, menyimpan, mengirim dan mengidentifikasi serta membedakan produk di pasar.

Home industry "INYAK" merupakan salah satu produsen makanan ringan, yang memproduksi keripik kentang. Ibu Fitri Madonna sebagai pemilik keripik kentang "INYAK" yang berlokasi di Piai Tanah Sirah kota Padang, dalam kegiatan usahanya menghasilkan produk keripik kentang yang dikemas dalam kemasan namun kemasan yang digunakan masih terbilang sederhana yaitu menggunakan plastik bening yang biasa dipakai oleh beberapa home industry. Disamping itu kemasan yang ada saat ini juga kurang memberikan informasi komposisi yang terkandung didalamnya dan informasiinformasi penting lainnya serta bentuk kemasan yang monoton sehingga kurang bisa menarik daya minat konsumen.

Agar lebih terarahnya penelitian yang penulis lakukan, maka penulis membuat batasan masalahnya sebagai berikut: Peneliti hanya membahas karakteristik kemasan yang representatif untuk produk keripik kentang produksi home industry "INYAK".

Penjualan keripik kentang "INYAK" masih menggunakan kemasan yang sangat sederhana. Hal ini mnejadi faktor penghambat pemasaran keripik kentang. Home industry "INYAK" memiliki target penjualan sebanyak $100 \mathrm{~kg} /$ minggu. Namun, data penjualan yang diperoleh dari home industry "INYAK" dalam tiga bulan terakhir yaitu sebanyak $480 \mathrm{~kg}$, sementara target penjualan yang harus dicapai 
sebanyak $1200 \mathrm{~kg}$ dalam tiga bulan. Oleh sebab itu perlu dilakukan penelitian terkait desain kemasan untuk membantu meningkatkan pemasaran keripik Inyiak.

Berdasarkan rumusan masalah yang telah dirumuskan, maka tujuan dari dilakukannya penelitian ini adalah : Mengetahui karakteristik kemasan yang representatif untuk produk keripik kentang produksi home industri "INYAK" serta mengetahui harapan dan keinginan konsumen terhadap kemasan yang representatif untuk keripik kentang home industry "INYAK".

\section{METODE PENELITIAN}

Dalam pelaksanaan penelitian ini, pengambilan data dilakukan pada home industry keripik kentang "INYAK" Jl. Piai Tanah Sirah RT 05 RW 06 No. 23, Kelurahan Piai Tanah Sirah, Kecamatan Lubuk Begalung, Kota Padang.

Jenis penelitian ini adalah penelitian kuantitatif yang lebih menekankan pada aspek pengukuran secara obyektif terhadap fenomena sosial yang dijabarkan ke dalam beberapa komponen masalah, variabel dan indikator. Data primer dikumpulkan dengan metode survei berupa wawancara berdasarkan kuesioner yang diberikan kepada responden yang pernah mengkonsumsi keripik kentang "INYAK". Data sekunder adalah data pendukung yang diperoleh dari sumber lain diluar objek penelitian yang diperoleh melalui studi kepustakaan.

Jumlah sampel yang digunakan dalam penelitian ini sebanyak 100 responden diperoleh dengan metode Solvin dimana populasi berukuran besar dengan jumlah tidak diketahui. Data-data yang diperoleh melalui wawancara dan pengukuran langsung kemudian dianalisa, sehingga dapat dilakukan pembuatan House Of Quality.

Langkah-langkah yang harus ditempuh dalam membangun HoQ sebagai berikut:
Identifikasi konsumen atau user atau pemakai, permulaan QFD adalah dengan menggariskan apa yang akan diselesaikan pada produk berdasarkan kehendak konsumen.

Menentukan Customer needs-nya (WHATs), customer need sering juga disebut dengan voice of the customer. Item ini mengandung hal-hal yang dibutuhkan oleh konsumen dan masih bersifat umum, sehingga sulit untuk langsung diimplementasikan. customer need dapat dilakukan dengan melalui penelitian terhadap keinginan konsumen.

Menentukan importance rating, merupakan tingkan kepentingan dari voice of customer dan hasil perhitungan kuisoner yang disebarkan kepada pelanggan. Perhitungan kuisoner atau pernyataan kuisoner ini biasa dilakukan dengan berbagai cara baik dengan menggunakan skala likert ataupun menggunakan matrik pyramid comparison.

Menentukan tecnical requirements (HOWs), tecnical requirements merupakan pengembangan dari customer need atau merupakan terjemahan kebutuhan konsumen dalam bentuk teknis agar sebuah produk dapat dibentuk secara langsung.

Menentukan relationship, agar diperoleh nilai secara komulatif maka antara what dan how merupakan langkah selanjutnya untuk menemukan nilai bobot. Menggambarkan hubungan menggunakan simbol-simbol, simbol-simbol yang pada umumnya digunakan dalam penjelasan hubungan tersebut, antara lain :

- adalah menggambarkan hubungan yang kuat dengan nilai bobot 9

$\square$ adalah menggambarkan hubungan yang sedang dengan bobot 3 .

$\Delta$ adalah menggambarkan hubungan yang lemah dengan bobot 1 .

Menetukan bobot, bobot ditentukan dari hubungan korelasi antara customer requirement dan technical requirement yang ditentukan dari jenis hubungan yang 
berlangsung. Hubungan ini dapat dirumuskan sebagai berikut :

$\mathrm{NPj}=(\mathrm{TKi} \times \mathrm{Nhij})$

dimana :

$\mathrm{NPj}$ : Nilai prioritas karakteristik teknik ke-j

TKi : Tingkat kepentingan konsumen ke-i

Nhij : Nilai hubungan karakteristik teknik ke-j dengan

kebutuhan konsumen i

Menentukan aksi terhadap pengembangan produk baru, aksi terhadap pengembang produk baru ditentukan melalui strategi analisa dalam HoQ.

\section{HASIL DAN PEMBAHASAN}

\section{Identifikasi kebutuhan konsumen}

Kebutuhan konsumen dalam HoQ berisi suatu daftar suara konsumen (voice of customer). Kebutuhan konsumen ini didapat dari kuesioner utama yang disebarkan. Dari kuesioner ini akan didapatkan suara konsumen yang menggambarkan harapan konsumen terhadap kemasan keripik kentang. Dalam pengolahannya semua item pertanyaan lulus uji validasi, Rekapitulasi kebutuhan konsumen tersebut dapat dilihat pada Tabel 1 .

Tabel 1 Rekapitulasi Kebutuhan Konsumen

\begin{tabular}{|c|c|c|}
\hline No & Dimensi & Kebutuhan Konsumen \\
\hline \multirow{5}{*}{1} & \multirow{5}{*}{ Keandalan } & a. Kemasan menjaga kebersihan isi produknya \\
\hline & & $\begin{array}{l}\text { b. Kemasan mampu menjaga kandungan produk dari bau } \\
\text { menyengat }\end{array}$ \\
\hline & & c. Kemasan kuat melindungi produk \\
\hline & & d. Kemasan mudah dipajang \\
\hline & & e. Kemasan sesuai dengan ukuran dan berat produk \\
\hline \multirow{5}{*}{2} & \multirow{5}{*}{ Fitur } & a. Identitas kemasan produk jelas \\
\hline & & b. Kemasan memberikan informasi komposisi produk \\
\hline & & c. Kemasan memberikan informasi tanggal kadaluarsa \\
\hline & & d. Kemasan menampilakn izin usaha \\
\hline & & e. Kemasan memberikan informasi alamat produsen \\
\hline \multirow[t]{3}{*}{3} & \multirow[t]{3}{*}{ Estetika } & $\begin{array}{l}\text { a. Warna kemasan menarik, sesuai dengan produk dan } \\
\text { sasaran pasar }\end{array}$ \\
\hline & & b. Bentuk kemasan menarik \\
\hline & & c. Terdapat gambaran produk pada kemasan \\
\hline \multirow[b]{2}{*}{4} & \multirow[b]{2}{*}{ Kesesuain } & a. Ukuran kemasan praktis untuk dibawa \\
\hline & & $\begin{array}{l}\text { b. Kemasan mudah dipegang dengan hanya } \\
\text { menggunakan satu tangan }\end{array}$ \\
\hline \multirow{3}{*}{5} & \multirow{3}{*}{$\begin{array}{l}\text { Persepsi Terhadap } \\
\text { Kualitas }\end{array}$} & a. Desain kemasan mudah diingat \\
\hline & & $\begin{array}{l}\text { b. Desain kemasan menggambarkan identitas/ karakter } \\
\text { elegan dari produk }\end{array}$ \\
\hline & & c. Brand / Merek sudah menarik dalam persaingan \\
\hline
\end{tabular}

\section{Penentuan Tingkat Kepentingan}

Konsumen

Setelah kebutuhan konsumen diperoleh, langkah selanjutnya adalah menghitung Tingkat Kepentingan Konsumen yang menunjukkan nilai prioritas kebutuhan konsumen. Nilai ini digunakan untuk menentukan skala prioritas apa saja dari suara konsumen yang harus dikembangkan oleh pengembang terlebih dahulu. Adapun contoh perhitungan menentukan tingkat kepentingan konsumen untuk item pertanyaan no 1 "Kemasan menjaga kebersihan isi produknya" adalah:

$\mathrm{f} 1=70$

$\mathrm{f} 2=28$

$\mathrm{f} 3=2$

$\mathrm{f} 4=0$

$\mathrm{f} 5=0$

$\mathrm{N}=100$

$T K K=\frac{(f 1 \times 5)+(f 2 \times 4)+(f 3 \times 3)+(f 4 \times 2)+(f 5 x 1)}{30}$

$T K K=\frac{(70 \times 5)+(28 \times 4)+(2 \times 3)+(0 \times 2)+(0 \times 1)}{100}$

$\mathrm{TKK}=4.68$

Skala pengukuran yang digunakan adalah skala likert yang berbentuk diskret, maka nilai yang diperoleh dibulatkan menjadi lima. Akan tetapi untuk perhitungan nilai prioritas digunakan nilai dalam bentuk bilangan ril.

\section{Karakteristik Teknik}

Karakteristik teknik merupakan suara pengembang. Data karakteristik teknik untuk desain kemasan keripik kentang ini diperoleh dengan pencarian literatur di situs web http://www.ahlidesain.com dan melakukan diskusi bersama Bapak Armizal beliau merupakan pemilik usaha desain grafis di kota padang yang memiliki pengalaman kerja kurang lebih 12 tahun. Dan beliau juga berpengalaman dalam meredesain permintaan - permintaan konsumennya. Adapun rekapitulasi karakteristik teknik untuk kemasan keripik kentang dapat dilihat pada Tabel 2 . 
Tabel 2 Rekapitulasi Karakteriktik Teknik

Untuk Kemasan Keripik Kentang

\begin{tabular}{|c|l|}
\hline No & \multicolumn{1}{|c|}{ Karakteristik Teknik } \\
\hline 1 & Dimensi kemasan \\
\hline 2 & Ergonomic desain \\
\hline 3 & Penggunaan bahan kemasan \\
\hline 4 & Fitur kemasan \\
\hline 5 & Ketahan bahan kemasan \\
\hline 6 & Barrier perlindungan dari setiap kontaminasi luar \\
\hline 7 & Struktural integritas dan perlindungan produk \\
\hline 8 & Desain grafis \\
\hline 9 & Kualitas pengemasan \\
\hline
\end{tabular}

4. Matrik Hubungan Keinginan Konsumen Dengan Karakteristik Teknik

Di bagian ini akan dilakukan penilaian hubungan antara keinginan konsumen dengan karakteristik teknik. Hubungan ini dibuat dalam bentuk matriks dengan menggunakan simbol-simbol yang ada. Dalam melakukan penilaian hubungan antara kebutuhan konsumen dengan karakteristik teknik, hal yang dilakukan adalah memperhatikan kriteria hubungan dan kemudian memberikan nilai yang sesuai dengan hubungan yang terbentuk. Penilaian hubungan ini dilakukan berdasarkan hasil dari diskusi dengan Bapak Armizal, ST.

Berikut uraian hubungan antara keinginan konsumen dengan karakteristik teknik :

Kemasan menjaga kebersihan isi produknya memiliki hubungan yang kuat (•) dengan karakteristik teknik kualitas pengemasan, karena kemasan yang dapat menjaga kebersihan produknya tergantung juga pada kualitas dalam pengemasan produk saat dan ketika produk akan. Sementara hubungan kemasan menjaga kebersihan isi produknya memiliki hubungan sedang (o) dengan karakteristik teknik ergonomic desain, penggunaan bahan kemasan, ketahan bahan kemasan, dan barrier perlindungan dari setiap kontaminasi luar karena ketiga karakteristik ini dapat menjaga kebersihan suatu produk.
Kemasan mampu menjaga kandungan produk dari bau menyengat memiliki hubungan yang kuat (•) dengan karakteristik teknik ketahanan bahan kemasan, barrier perlindungan dari setiap kontaminasi luar dan kualitas pengemasan. Sementara hubungan Kemasan mampu menjaga kandungan produk dari bau menyengat memiliki hubungan mungkin $(\Delta)$ dengan ergonomic desain dan struktural integritas dan perlindungan.

Kemasan kuat melindungi produk memiliki hubungan yang kuat (•) dengan karakteristik teknik penggunaan bahan kemasan, ketahanan bahan kemasan serta dengan barrier struktural integritas dan perlindungan. Sementara hubungan kemasan kuat melindungi produk memiliki hubungan sedang (o) dengan karakteristik teknik kualitas pengemasan, Sementara hubungan kemasan kuat melindungi produk memiliki hubungan mungkin $(\Delta)$ dengan fitur kemasan.

Kemasan mudah dipajang memiliki hubungan yang kuat (•) dengan karakteristik teknik ergonomic desain, ketahanan bahan kemasan serta dengan barrier struktural integritas dan perlindungan. Sementara hubungan kemasan mudah dipajang memiliki hubungan sedang (o) dengan penggunaan bahan kemasan, disamping itu hubungan kemasan mudah dipajang memiliki hubungan mungkin $(\Delta)$ dengan fitur kemasan.

Kemasan sesuai dengan ukuran dan berat produk memiliki hubungan yang kuat (•) dengan karakteristik teknik dimensi kemasan. Sementara hubungan kemasan sesuai dengan ukuran dan berat produk memiliki hubungan sedang (o) dengan ergonomic desain, disamping itu hubungan kemasan sesuai dengan ukuran dan berat produk memiliki hubungan mungkin $(\Delta)$ dengan kualitas pengemasan

Identitas produk jelas hanya memiliki hubungan yang kuat $(\bullet)$ 
dengan karakteristik teknik fitur kemasan.

Kemasan memberikan informasi produk juga hanya memiliki hubungan yang kuat (•) dengan karakteristik teknik fitur kemasan.

Kemasan memberikan informasi kadaluarsa juga hanya memiliki hubungan yang kuat (•) dengan karakteristik teknik fitur kemasan.

Kemasan menampilkan izin usaha juga hanya memiliki hubungan yang kuat (•) dengan karakteristik teknik fitur kemasan. Kemasan menampilkan alamat produsen juga hanya memiliki hubungan yang kuat (•) dengan karakteristik teknik fitur kemasan.

Warna kemasan menarik sesuai dengan produk dan sasaran pasar memiliki hubungan yang kuat (•) dengan karakteristik teknik desain grafis. Sementara hubungan warna kemasan menarik sesuai dengan produk dan sasaran pasar memiliki hubungan mungkin $(\Delta)$ dengan fitur kemasan.

Bentuk kemasan menarik memiliki hubungan yang sedang (o) dengan karakteristik teknik dimensi kemasan dan ergonomic desain.

Terdapat gambaran produk pada kemasan memiliki hubungan yang kuat (•) dengan karakteristik teknik fitur kemasan dan desain grafis.

Ukuran kemasan praktis untuk dibawa memiliki hubungan yang kuat $(\bullet)$ dengan karakteristik teknik dimensi kemasan. Sementara hubungan Ukuran kemasan praktis untuk dibawa memiliki hubungan sedang (o) dengan karakteristik teknik ergonomic desain.

Kemasan mudah dipegang dengan hanya menggunakan satu tangan memiliki hubungan yang kuat $(\bullet)$ dengan karakteristik teknik ergonomic desain. Sementara hubungan Kemasan mudah dipegang dengan hanya menggunakan satu tangan memiliki hubungan sedang (o) dengan karakteristik teknik dimensi kemasan.
Desain kemasan mudah diingat memiliki hubungan yang kuat (•)dengan karakteristik teknik fitur kemasan dan desain grafis. Sementara hubungan desain kemasan mudah diingat memiliki hubungan mungkin $(\Delta)$ dengan dimensi kemasan.

Desain kemasan menggambarkan idntitas karakter elegan memiliki hubungan yang kuat (•) dengan karakteristik teknik fitur kemasan dan desain grafis.

Brand / merek menarik dalam persaingan memiliki hubungan yang kuat (•) dengan karakteristik teknik fitur kemasan dan desain grafis. Nilai prioritas karakteristik teknik.

Nilai prioritas karaktristik teknik ini dapat mengambarkan bagian mana dari karakteristik teknik yang akan dijadikan prioritas dalam pengembangan produk. Perhitungan nilai prioritas karakteristik dilakukan dengan cara mengalikan tingkat kepentingan konsumen dengan nilai hubungan dalam bentuk simbol yang terdapat pada matriks hubungan keinginan konsumen dengan karakteristik teknik. Berikut rekapitulasi nilai prioritas absolut karakteristik teknik dapat dilihat pada Tabel 3.

Tabel 3 Rekapitulasi Nilai Prioritas Absolut Karakteristik Teknik

\begin{tabular}{|c|l|c|}
\hline No & \multicolumn{1}{|c|}{ Karakteristik Teknik } & Bobot Relatif \\
\hline 1 & Fitur Kemasan & $31.24 \%$ \\
\hline 2 & Desain grafis & $16.74 \%$ \\
\hline 3 & Ergonomic desain & $11.24 \%$ \\
\hline 4 & Dimensi kemasan & $9.18 \%$ \\
\hline 5 & Kualitas pengemasan & $8.76 \%$ \\
\hline 6 & Ketahan bahan kemasan & $8.32 \%$ \\
\hline 7 & Penggunaan bahan kemasan & $5.75 \%$ \\
\hline 8 & Barrier perlindungan dari setiap kontaminasi luar & $4.80 \%$ \\
\hline 9 & Struktural integritas dan perlindungan produk & $3.94 \%$ \\
\hline \multicolumn{2}{|c|}{ Sumber : Data pengolahan nilai prioritas } \\
\hline
\end{tabular}

\section{KESIMPULAN}

Dari hasil penelitian dan pembahasan dari bab-bab sebelumnya didapat suatu kesimpulan dalam Penentuan Kemasan yang Representatif pada Keripik Kentang Home Industry "INYAK" menghasilkan : 
1. Karakteristik kemasan yang representatif untuk produk keripik kentang home industry "INYAK" adalah :

a. Fitur kemasan

b. Desain grafis

c. Ergonomic desain

d. Dimensi kemasan

e. Kualitas pengemasan

f. Ketahanan bahan kemasan

g. Penggunaan bahan kemasan

h. Barrier perlindungan dari setiap kontaminasi luar

i. Struktural integritas dan perlindungan produk

Data diatas disusun berdasarkan nilai prioritas tertinggi sampai ke yang terendah dimana fitur kemasan menjadi nilai prioritas tertinggi dengan nilai $31.24 \%$

2. Harapan konsumen terhadap keripik kentang yang representatif pada home industry "INYAK" adalah :

a. Kemasan menjaga kebersihan produknya

b. Kemasan mampu menjaga kandungan produk dari bau menyengat

c. Kemasan kuat melindungi produk

d. Brand / Merek menarik dalam persaingan

e. Kemasan memberikan nilai kadaluarsa

f. Warna kemasan menarik berimbang dengan produk dan sasaran pasar

g. Kemasan berimbang dengan ukuran dan berat produk

h. Identitas kemasan produk jelas

i. Kemasan memberikan informasi komposisi produk

j. Kemasan menampilkan izin usaha

k. Desain kemasan menggambarkan identitas/ karakter elegan dari produk

1. Bentuk kemasan menarik

m. Desain kemasan mudah diingat

n. Terdapat gambaran produk pada kemasan o. Ukuran kemasan praktis untuk dibawa

p. Kemasan memberikan informasi alamat produsen

q. Kemasan mudah dipajang

r. Kemasan mudah dipegang dengan hanya menggunakan satu tangan

Data diatas disusun berdasarkan nilai Tingkat Kepentingan Konsumen (T.K.K) tertinggi hingga yang terendah, dimana kemasan menjaga kebersihan produknya memiliki nilai T.K.K sebesar 4,68.

\section{DAFTAR PUSTAKA}

Abhilasha Pathak, The cognitive power of product Packaging, IOSR Journal of Business and Management (IOSRJBM) e-ISSN: 2278-487X, pISSN: 2319-7668. Volume 16, Issue 7. Ver. II (July. 2014), PP 61- 64

Christine Suharto Cenadi, Peranan desain kemasan dalam dunia pemasaran, NIRMANA Vol. 2, No. 1, Januari 2000: $92-103$.

Drs.Sumanto.M.A, Metodologi Penelitian Sosial dan Pendidikan, Yogyakarta : Andi Offset, 1995.

Ervil, Riko, dkk, Buku Panduan Penulisan dan Ujian Skripsi, STTIND Padang, Padang, 2012.

Garspersz, Vincent, Total Quality Management. Jakarta: Penerbit Erlangga, 2006

Halim, V. and Ekawati, Y. (2014). Perencanaan Produk Olahan Wortel Menggunakan Metode Quality Function Deployment. Symbol, Vol. 1, no. 1, pp 57-67.

Iqbal, Hasan, Analisis Data Penelitian Dengan Statistik. Penerbit Bumi Aksara. Jakarta, 2004. 
J, Mahesh Patil. 2010. Quality Function Deployment (QFD) for Product Design. India : TIME 2010.

Kotler, Philip, Manajemen Pemasaran Analisa, Perencanaan, Implementasi, dan Kegunaan, Edisi Kedelapan, Salemba Empat, Jakarta, 1995.

Luthfianto, S \& Suwandono. 2010. "Penerapan Metode Quality Function Deployment Untuk Meningkatkan Produk Kain Batik Tulis Yang Berkualitas Di Desa Cibelok Kecamatan Taman

Pamungkas, Bambang dan Lina Miftahul Jannah, Metode Penelitian Kuantitatif: Teori dan Aplikasi.Jakarta: PT RajaGrafindo Persada, 2006.

Prasad, M. V. dan Chandra S. P. 2013. A Study on Implementation of Quality Function Deployment Technique in Product Design Stage. International Journal of Management Research and Review 3:6, 2966 - 2974

Santoso, Singgih, Mengolah Data Statistik Secara Profesional. PT. Alex Media Komputindo. Jakarta, 2001

Sukaria, Sinulingga. Metode Penelitian. Sumatra Utara : USU Press. 2011

Supranto, J, Pengukuran Tingkat Kepuasan Pelanggan untuk Menaikkan Pangsa Pasar, Rineka Cipta, 2006..

Tatang M. Amirin, Skala Likert : Penggunaannya dan Analisis Datanya, 2010

Yamit, Zulian, Manajemen Kualitas Produk dan Jasa. Ekonesia, Yogyakarta, 2011. 